\title{
As possibilidades de crise inscritas na reprodução do capital social
}

\author{
The possibilities of crisis inscribed in the reproduction of social capital
}

\begin{abstract}
Resumo: Este artigo tem como objetivo analisar o processo de reprodução do capital social a fim de identificar em quais pontos deste processo as possibilidades de crise estão inscritas. Trata-se de uma análise teórica acerca das crises econômicas que resgata o método de investigação de Marx tomando como instrumental de análise o conceito de contradição. Primeiro, apresenta-se uma revisão do significado do termo contradição nas obras de Marx e em especial nos trechos em que o autor se ocupa da análise das possibilidades de crise. Em seguida utilizam-se os esquemas da reprodução de Marx a fim de identificar os pontos nos quais contradições existentes colocam possibilidades de crise inscritas na reprodução do capital social. Assim, conclui-se que o entendimento das crises concretas, portanto, reais, requerem diversas mediações, as quais não estão contempladas nos esquemas de reprodução dada sua natureza abstrata.
\end{abstract}

Palavras-chave: Crise; Contradição; Capital Classificação JEL: B14, E11, P16

\begin{abstract}
This article aims to analyze the process of reproduction of social capital in order to identify in this process the possibilities of crisis which are inscribed in it. This is a theoretical analysis of economic crises that recovers Marx's method of investigation, taking the concept of contradiction as an analytical tool. First, it presents a review of the meaning of the term contradiction in Marx's works and especially in the passages in which the author deals with the analysis of the possibilities of crisis. Next, Marx's reproduction schemes are used in order to identify the points at which existing contradictions pose possibilities of crisis inscribed in the reproduction of social capital. By "possibility of crisis" we understand the crisis in its abstract form. Thus, it is concluded that the understanding of concrete crises, therefore real, require several mediations, which are not contemplated in the reproduction schemes given their abstract nature.
\end{abstract}

Keywords: Crisis; Contradiction; Capital

JEL Classification: B14, E11, P16

${ }^{\text {a }}$ Professora do Departamento de Economia da Universidade Federal do Paraná (DEPECON/UFPR). Email: dayani.aquino@gmail.com. 


\section{Introdução}

As teorias de crise marxistas não apresentam consenso no que se refere aos mecanismos causais da crise ${ }^{1}$. Os apontamentos de Marx sobre crise, dispersos em trechos de O Capital e das Teorias da mais valia nos indicam que a explicação para as crises reais deve ser consistente com o método de análise que parte do abstrato ao concreto. Neste sentido, é preciso mostrar que as crises reais só podem ser a realização de algo que já existia como possibilidade, algo que era latente dentro do processo de reprodução do capital.

Tendo isso em vista, o objetivo do presente trabalho é partir do conceito de contradição para investigar as possibilidades de crise inscritas na reprodução do capital social . Portanto, não se trata de investigar uma crise real que já ocorreu ou de elaborar uma teoria que explique o mecanismo causal geral das crises. $\mathrm{O}$ objetivo consiste, apenas, em mapear ao longo do processo de reprodução do capital social - utilizando-se dos esquemas de reprodução de Marx - os pontos em que contradições existentes indiquem possibilidades de crise. Vale notar que os esquemas de reprodução foram construídos por Marx em um alto nível de abstração, portanto, a análise da reprodução do capital social extraída destes esquemas encontram-se igualmente em alto nível de abstração, por esta razão só é possível retirar deles indicações sobre as possibilidades de crise e não sobre as crises reais.

Assim, para atender a este objetivo o artigo está dividido em 4 seções incluindo esta introdução. A seção 2 discute o conceito de contradição buscando o entendimento do próprio Marx acerca deste conceito. Em seguida, relacionamos o conceito de contradição e o conceito de possibilidade de crise. Na seção 3 utilizamos os esquemas de reprodução do capital social a fim de mapear as contradições existentes que colocam possibilidades de crise. Por último são apresentadas as considerações finais.

\section{O Significado da Contradição e da Possibilidade de Crise}

Em O Capital, e nas Teorias da Mais-Valia, Marx expressa a relação entre as contradições e as crises assim: "As crises são sempre apenas soluções momentâneas violentas das contradições, irrupções violentas que restabelecem momentaneamente o

\footnotetext{
${ }^{1} \mathrm{O}$ estado da arte das teorias de crise já foi exaustivamente explorado na literatura marxista. Uma classificação possível destas teorias é apresentada por Itoh (1980) dividindo-as em dois grupos: (i) Teorias de excesso de mercadoria, que inclui as vertentes subconsumistas e da desproporção dos ramos industriais (autores considerados subconsumistas são Baran e Sweezy (1964) e Luxemburgo (1985), embora esta última não seja considerada por Bleaney (1976) como subconsumista, pois, segundo o autor, ela não se ocupa especificamente da deficiência na demanda de bens de consumo; um autor considerado teórico da desproporção é Hilferding (1985), embora Zoninsein (1985) destaque duas concepções contraditórias sobre a causa da crise na obra de Hilferding: as desproporções e uma outra baseada na lei da queda tendencial da taxa de lucro; e (ii) Teorias de excesso de capital, que inclui a hipótese de aumento da composição orgânica do capital e da escassez de força de trabalho (um autor que explica a crise por meio do aumento da composição orgânica do capital é Shaikh (1979) e a explicação da crise por meio da escassez de força de trabalho é dada por Itoh (1980), entre outros).
} 
equilíbrio perturbado.” (MARX, 1986, v. IV, p.188; MARX, 1980, p. 945). Com isso, se as crises estão relacionadas às contradições do capitalismo, então é preciso entender qual o significado da palavra contradição quando Marx se refere às crises para, em seguida, entender o que é a possibilidade da crise. Entender o significado de contradição é decisivo para podermos identificá-las e mapeá-las dentro do processo de reprodução do capital.

Karl Marx não escreveu um texto que explicasse a diferença entre o seu conceito de contradição e o conceito hegeliano , e como o tema Hegel-Marx já foi exaustivamente discutido na literatura marxista não se pretende voltar a analisá-lo aqui, uma vez que nos interessa buscar no próprio Marx o sentido do termo contradição. Esta estratégia traz, ao mesmo tempo, o entendimento do conceito e de sua relação com a possibilidade de crise.

Como observam Zelený (1974) e Bhaskar (1988) a palavra contradição é utilizada por Marx com significações diversas de acordo com os vários contextos possíveis. De modo geral é possível dividir os significados em dois grupos: as contradições não-dialéticas e as contradições dialéticas. Bhaskar chama atenção para dois aspectos importantes que caracterizam as contradições dialéticas marxistas: "(i) constituem oposições inclusivas reais, já que seus termos pressupõem existencialmente seu oposto; (ii) são sistemáticas ou internamente relacionadas com uma forma de aparência mistificadora". (BHASKAR, 1988 , p. 80). Esta forma de definir a contradição dialética como uma oposição inclusiva nos permite identificar dois elementos da contradição: a inclusão e a oposição. A inclusão expressa a unidade de dois polos. A oposição expressa a independência, a separação, a dissociação, ou, ainda, a autonomização destes dois polos. Assim sendo, tentaremos demonstrar, com base em citações do próprio Marx, que o significado da contradição, ao menos quando associada à temática da crise, consiste na unidade de elementos opostos que, por serem opostos, podem assumir independência e separarem-se. O fato de poderem assumir tal independência coloca a possibilidade de crise ou revelam a forma abstrata da crise.

Bhaskar divide, ainda, as contradições dialéticas em: (i) contradições dialéticas históricas; e (ii) contradições dialéticas estruturais (BHASKAR, 1988, p.80). Para o objetivo do presente trabalho nos concentraremos na análise daquilo que Bhaskar chama de contradições dialéticas estruturais, que são contradições decorrentes da natureza específica do capitalismo e, portanto, existem apenas neste modo de produção devido às estruturas exclusivas encontradas nele.

Para Bhaskar, as contradições dialéticas estruturais mais importantes são "as que existem entre os aspectos concretos úteis e os aspectos sociais abstratos do trabalho e entre o valor de uso e o valor da mercadoria - que se manifesta na distinção entre as formas de valor relativas e equivalentes, e se exteriorizam nas contradições entre mercadoria e dinheiro e trabalho assalariado e capital." (BHASKAR, 1988, p.80). Assim, com base nesta indicação de Bhaskar, serão analisadas algumas passagens importantes das obras Grundrisse, Teorias da Mais-Valia e O Capital buscando-se identificar o desenvolvimento destas contradições dialéticas estruturais em três níveis de análise, partindo da relação mais simples e abstrata em direção a relações mais complexas, mas que ainda se encontram em 
alto nível de abstração: 1) relação entre valor e valor de uso; 2) relação entre mercadoria e dinheiro; 3 ) relação entre compra e venda.

Nos Grundrisse já encontramos o desenvolvimento lógico dessas contradições. Primeiro Marx apresenta a contradição mais elementar, isto é, entre o valor de uso e o valor da mercadoria. Esta contradição é fundamental pelo fato de que dará origem ou se “exteriorizará” na contradição entre a mercadoria e o dinheiro para, então, fazer emergir a contradição entre as fases de compra e venda, ambas contidas no processo de metamorfose da mercadoria, processo este que se manifesta na circulação simples da mercadoria, no circuito do capital e na reprodução do capital social.

Na referida obra, Marx ainda não utiliza o termo valor de uso em contraposição ao termo valor, mas essa contradição é expressa por meio da dupla existência da mercadoria como valor e como produto:

Sua propriedade de ser valor não somente pode, mas deve alcançar uma existência diferente da sua natural. Por quê? Porque as mercadorias enquanto valores são diferentes umas das outras apenas quantitativamente; então cada mercadoria deve ser qualitativamente diferente de seu próprio valor. Seu valor deve conseqüentemente ter uma existência que seja qualitativamente distinguível dele. Na troca real esta separação deve transformar-se numa separação real, porque a distinção natural das mercadorias deve manifestar-se na contradição com sua equivalência econômica, e porque ambos só podem existir juntos se a mercadoria alcançar uma existência dupla, não somente natural, mas também uma existência puramente econômica. (MARX, 1993, p.141).

Por um lado, a existência da mercadoria como valor implica sua existência enquanto resultado do trabalho humano e, portanto, enquanto portadora de certa quantidade de trabalho. Por outro lado, a existência da mercadoria como produto implica sua existência enquanto portadora de propriedades naturais, isto é, as características da mercadoria de satisfazer necessidades humanas, ou seja, seu valor de uso.

Assim, a contradição entre valor e valor de uso contempla a unidade e a dissociação dos elementos que se opõe, isto é, do valor e do valor de uso. A unidade se verifica no fato de que o objeto que tem valor (quantidade de trabalho incorporada), mas não tem valor de uso (não é útil, no sentido de não ser capaz de satisfazer nenhuma necessidade humana) não é mercadoria. Por outro lado, o objeto que tem valor de uso, mas não tem valor de troca (no sentido de que não é produzido com a intenção de troca) também não é mercadoria. Portanto, os polos da oposição (valor e valor de uso) se pressupõem mutuamente formando a mercadoria. A dissociação entre valor e valor de uso se expressa na autonomização (exteriorização) da mercadoria ao lado do dinheiro. Portanto, a contradição entre valor e valor de uso é a forma mais abstrata da crise e coloca a possibilidade de crise no seu nível mais abstrato.

Marx demonstra esta exteriorização da contradição interna entre valor e valor de uso na derivação da forma dinheiro que, nos Grundrisse, é ainda parcialmente desenvolvida em comparação com a exposição encontrada em $O$ Capital. Conforme Marx, o valor da mercadoria enquanto forma de existência separada de seu valor de uso deve existir ao lado dela como uma mercadoria própria. Portanto, deve expressar-se num equivalente geral, isto 
é, no dinheiro, de modo que as mercadorias possam ser mensuradas, equiparadas e finalmente trocadas. Portanto, a necessidade de expressar o valor separadamente do valor de uso da mercadoria autonomiza o dinheiro ao lado da própria mercadoria, enquanto produto, isto é, enquanto valor de uso. Assim, a contradição interna entre o valor de uso e o valor da mercadoria se expressa na contradição externa entre mercadoria e dinheiro:

A mesma contradição entre a natureza particular da mercadoria enquanto produto e sua natureza geral enquanto valor de troca, que criou a necessidade de apresentá-la duplamente, como mercadoria particular, de um lado, e como dinheiro, de outro - esta contradição entre as qualidades naturais particulares da mercadoria e suas qualidades sociais gerais contém desde o início a possibilidade de que estas duas formas separadas em que a mercadoria existe não sejam conversíveis uma na outra. (MARX, 1993, p. 147).

Portanto, a contradição entre a mercadoria e o dinheiro carrega a possibilidade de que uma mercadoria não possa se converter na outra, ou seja, de que uma mercadoria não possa, por razões diversas, se converter em dinheiro, portanto, contém de forma latente a possibilidade da crise. Finalmente, a forma mais desenvolvida da contradição se expressa na contradição entre a compra e a venda:

\begin{abstract}
Apenas enquanto o valor de troca da mercadoria a conduz a uma dupla existência, como mercadoria particular e como dinheiro, então o ato de troca divide-se em dois atos mutuamente independentes: troca de mercadorias por dinheiro, troca de dinheiro por mercadorias; compra e venda. Desde que estes atos alcançaram uma forma de existência separada espacial e temporalmente e mutuamente indiferente, sua identidade imediata cessa. Podem corresponder-se ou não; podem balancear-se ou não; podem entrar em desproporção um com o outro. (MARX, 1993, p. 148).
\end{abstract}

Aqui vale notar que a unidade entre compra e venda não se refere às ações de troca que se estabelecem entre duas pessoas ou entre dois capitais distintos. É evidente que a cada compra existe uma venda correspondente, isso nada mais é do que uma identidade contábil. A unidade entre compra e venda que se configura em uma contradição refere-se à metamorfose da mercadoria, seja na circulação simples de mercadoria, no circuito do capital ou no processo de reprodução do capital social. Podemos ilustrar isso usando como exemplo o circuito do capital da Figura 1, em que D representa dinheiro e M representa mercadoria. A transformação de D em M representa para o capitalista industrial um dos polos da contradição, isto é, a compra (que está associada a uma venda, do ponto de vista contábil); a transformação de $\mathrm{M}^{\prime}$ em D' representa o outro polo da unidade, a venda ${ }^{2}$. Portanto, a unidade está na compra-venda ou venda-compra por parte do capitalista industrial. Do mesmo modo, a dissociação ocorre se o capitalista industrial após vender M'

\footnotetext{
${ }^{2}$ No primeiro momento, a dissociação entre venda (M'-D') e compra (D' - M') pode ocorrer por diversas razões. O capitalista pode simplesmente desejar entesourar e com isso não utilizará o dinheiro adquirido com a venda para comprar mais meios de produção e/ou contratar força de trabalho. Mas, pode ser também que o capitalista não encontre no mercado os meios de produção disponíveis e por esta razão é que a compra não se sucedeu à venda. Já no outro, a dissociação entre compra (D' - M') e venda (M' - D') decorre fundamentalmente de um problema de demanda.
} 
não realizar uma nova compra; ou se o capitalista industrial após comprar M não puder vender M'. Esta dissociação dos polos da unidade consiste na possibilidade da crise, isto é, indica a forma mais abstrata da crise.

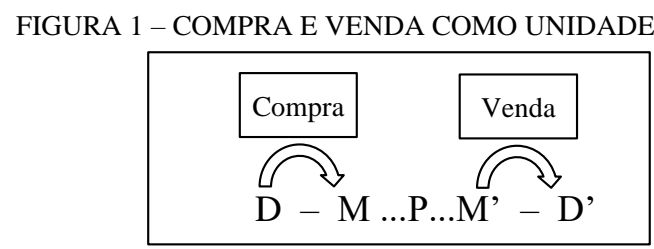

FONTE: Elaboração própria.

Em $O$ Capital Marx explica melhor a ideia de que a contradição existente entre compra e venda coloca a possibilidade de crise:

\begin{abstract}
Que os processos, que se confrontam autonomamente, formem uma unidade interna, significa por outro lado que a sua unidade interna se move em antíteses externas. Se a autonomização externa dos internamente não-autônomos por serem mutuamente complementares se prolonga até certo ponto, a unidade se faz valer de forma violenta, por meio de uma crise. A antítese, imanente à mercadoria, entre valor de uso e valor, de trabalho privado, que ao mesmo tempo tem de representar-se como trabalho diretamente social, de trabalho concreto particular, que ao mesmo tempo funciona apenas como trabalho geral abstrato, de personificação da coisa e reificação das pessoas - essa contradição imanente assume nas antíteses da metamorfose das mercadorias suas formas desenvolvidas de movimentos. Essas formas encerram, por isso, a possibilidade, e somente a possibilidade, das crises. $O$ desenvolvimento dessa possibilidade até que se realize exige todo um conjunto de condições que do ponto de vista da circulação simples de mercadorias, ainda não existem, de modo algum. (MARX, 1985, v. I, p. 100, destaques próprios).
\end{abstract}

Aqui vale ressaltar que a possibilidade de crise não pode explicar as crises reais, pois faltam diversos elementos concretos, como a concorrência e o crédito, que tem um papel importante na explicação das crises reais. Contudo, a explicação dos conflitos que produzem as crises reais devem demonstrar que "as formas mais abstrata dele são interativas e se contêm nas mais concretas." (Marx, 1980, p. 945, Teorias da mais valia). Nas Teorias da Mais-Valia, Marx desenvolve a relação da contradição e da possibilidade de crise, em duas passagens importantes:

Se, por exemplo, compra e venda - ou o movimento da metamorfose da mercadoria configura a unidade de dois processos, ou antes o decurso de um processo por meio de duas fases opostas, sendo na essência portanto a unidade de ambas as fases, esse movimento é também na essência a separação delas e a afirmação recíproca de independência. Mas, uma vez que estão interligadas, a afirmação de independência das fases vinculadas só se pode patentear de maneira violenta, como processo destrutivo. É justamente nas crises que sua unidade se manifesta, a unidade de elementos opostos. A independência recíproca assumida pelas duas fases conjugadas e complementares destrói-se à força. A crise, portanto revela a unidade dos elementos que passaram a ficar independentes uns dos outros. Não 
ocorreriam crises se não existisse essa unidade interna de elementos que parecem comportarse com recíproca indiferença. (MARX, 1980, p. 936, destaques próprios).

Ademais, crise é apenas a imposição violenta da unidade das fases do processo de produção, as quais se tornaram independentes umas das outras. (...) Assim, a forma mais abstrata da crise (e por isso a possibilidade formal da crise) é a metamorfose da mercadoria, a qual, como movimento desenvolvido, contém a contradição - encerrada na unidade da mercadoria entre valor de troca e valor de uso e ainda entre dinheiro e mercadoria. (MARX, 1980, p. 945 , destaques próprios).

Nesta passagem Marx deixa claro os dois elementos que caracterizam a contradição: a unidade e a ruptura. Fica evidente que a contradição, quando usada por Marx para se referir à crise, contém a unidade e a ruptura de elementos opostos.

Para finalizar, ainda é preciso esclarecer o que se entende pela expressão possibilidade da crise, já que nosso entendimento difere consideravelmente do entendimento apresentado por alguns autores como Shaikh (1988 e 1991) e Fine e Saad Filho (2004).

Shaikh, por exemplo, discute a possibilidade em contraposição à necessidade da crise. A diferença fundamental destas duas abordagens, segundo o autor, reside no entendimento da "lei de movimento" apresentada por Marx como resultado da interação entre tendências e contratendências. Nesta perspectiva, ele afirma que as "teorias da possibilidade" concebem as várias tendências e contratendências operando em pé de igualdade. Isto resulta numa noção de lei como o resultado de "tendências conflitantes" que podem ou não gerar a crise conforme a combinação de fatores historicamente determinados. Diferentemente disso, as "teorias da necessidade" baseiam-se na noção de lei "como expressão de uma tendência dominante intrínseca que subordina as tendências neutralizadoras" e por isso a crise resulta ser inevitável (Shaikh, 1988, p.86). Assim, para Shaikh, as teorias de crise subconsumistas e/ou estagnacionistas e as de compressão dos lucros pelos salários se enquadram na perspectiva das "teorias da possibilidade", enquanto que as teorias da tendência decrescente da taxa de lucro se enquadram no ponto de vista das "teorias da necessidade".

Neste mesmo sentido, a possibilidade da crise é entendida por Fine e Saad Filho (2004). Conforme estes autores, tanto as teorias de subconsumo quanto às de superprodução - as quais podem ser confundidas com as teorias das desproporções, pois indicam superprodução em um setor e subconsumo em outro - são "logicamente possíveis". Entretanto, para estes autores, elas são limitadas para explicar a causa da crise, pois deixam de lado o motivo orientador da produção capitalista: o lucro. Assim, eles argumentam que uma teoria da crise deveria explicar, entre outras coisas, porque a produção capitalista se expande além da possibilidade de sua realização lucrativa.

A partir destes dois entendimentos, observa-se que tanto na concepção de Shaikh quanto na de Fine e Saad Filho, a possibilidade da crise é uma situação na qual a crise pode ou não ocorrer. Nesta perspectiva, ambos os autores, demonstram certo favoritismo pelas teorias que tentam demonstrar a necessidade da crise, ou seja, o fato de que ela necessariamente ocorre. 
Contudo, na perspectiva do presente trabalho, o significado da possibilidade da crise difere deste entendimento, pois não se pretende contrapor a possibilidade à necessidade, mas ao contrário, pretende-se mostrar que a possibilidade da crise expressa apenas sua forma mais abstrata e na medida em que adquire conteúdo torna-se concreta, real e necessária. Assim, do ponto de vista metodológico, a possibilidade da crise é apenas o estágio mais abstrato e elementar da análise, em que alguns elementos da realidade da crise já estão contemplados, mas tantos outros ainda devem ser considerados. Tanto as formas abstratas da crise (sua possibilidade) quanto às formas concretas da crise (sua realidade) objetivam mostrar que o próprio modo de produção capitalista impõe a necessidade da crise. Deve-se notar, portanto, que tal concepção difere daquela apresentada anteriormente, pois não se trata de mostrar que a crise pode ou não ocorrer, mas sim de demonstrar que o modo de produção capitalista já contém desde suas formas mais elementares a possibilidade de ruptura e que essa possibilidade se torna realidade tão logo sejam inseridos na análise contradições cada vez mais concretas do processo de reprodução do capital. Portanto, a relação entre possibilidade e necessidade deve ser entendida, neste trabalho, elementos que coexistem dentro de um mesmo processo.

Esta concepção parece ser também a do próprio Marx quando este explica o que é a possibilidade da crise:

[...] quando dizemos que a forma simples da metamorfose encerra a possibilidade da crise, expressamos apenas que nesta própria forma está a possibilidade da ruptura e da dissociação de fases que na essência são complementares. [...] Possibilidade geral e abstrata da crise significa apenas a forma mais abstrata da crise, sem conteúdo, sem o impulso pertinente a esse conteúdo. [...] Assim, a forma mais abstrata da crise (e por isso a possibilidade formal da crise) é a metamorfose da própria mercadoria, a qual como movimento desenvolvido, contém a contradição [...] As crises do mercado mundial têm de ser concebidas como a convergência real e o ajuste à força de todas as contradições da economia burguesa. Os diversos fatores que convergem nessas crises têm portanto de ser destacados e descritos em toda esfera da economia burguesa, e, quanto mais nesta nos aprofundarmos, têm de ser detectadas novas características desse conflito, e ainda é mister demonstrar que as formas mais abstratas dele são interativas e se contém nas mais concretas. (MARX, 1980a, p. 944 945).

Marx acrescenta ainda que existem duas formas abstratas da crise, "em sua primeira forma, a crise é a metamorfose da própria mercadoria, a dissociação da compra e venda. Em sua segunda forma, a crise é a função do dinheiro como meio de pagamento, e então o dinheiro figura em duas fases diferentes, separadas no tempo, em dois papéis diversos. As duas formas são de todo abstratas, embora a segunda seja mais concreta que a primeira." (MARX, 1980, 945). Neste artigo, nos concentramos na análise da primeira forma apontada por Marx: e unidade e dissociação de compras e vendas.

Com estas definições de contradição e de possibilidade de crise passaremos à análise das contradições inscritas na reprodução do capital social. Vimos que a possibilidade de crise se desenvolve desde as formas mais abstratas - como brevemente analisado acima em que a contradição entre valor e valor de uso se exterioriza na 
contradição entre mercadoria e dinheiro que dá lugar à contradição entre compra e venda - até as formas mais concretas. A seguir serão buscados, nos esquemas de reprodução, os pontos da unidade e ruptura entre compras e vendas entre os departamentos. A análise permanece ainda no nível da possibilidade de crise, já que os esquemas abstraem vários elementos da atividade econômica concreta como a concorrência e o crédito.

\section{A Reprodução do Capital Social e as Possibilidades de Crise}

Os esquemas da reprodução, simples e ampliada, desenvolvidos por Marx foram apresentados, respectivamente, nos capítulos XX e XXI do livro II d' O Capital, publicado pela primeira vez em 1885. Esses esquemas consistem na divisão da economia capitalista em dois setores de atividades: (i) o setor produtor de meios de produção (máquinas, equipamentos, matérias primas etc), denominado por Marx como Departamento I; (ii) o setor produtor de meios de consumo (alimentos, roupas, calçados, bebidas etc.), nomeadamente, Departamento II.

Marx inicia sua exposição seguindo o seu método, que é partir do mais simples em direção ao mais complexo, por isso, ele inicia a análise com a apresentação do que chamamos de reprodução simples para somente depois avaliar como se dá a reprodução ampliada.

\subsection{Reprodução Simples do Capital Social}

A reprodução do capital social requer que ambos os departamentos de produção encontrem continuamente as condições materiais, do ponto de vista do valor de do valor de uso, para prosseguirem ano após ano. Da ótica do capital, é preciso que estejam disponíveis todos os meios de produção necessários para repor capital constante fixo e circulante e, ainda, que existam trabalhadores para serem empregados no processo produtivo. Da ótica dos indivíduos, é preciso que capitalistas e trabalhadores encontrem os meios de consumo requeridos para satisfazer suas necessidades biológicas, sociais, culturais etc. A reprodução do capital social requer, portanto, um intercâmbio equilibrado, um balanço, entre departamento I e II para que todo este processo se suceda sem crises, sem interrupções.

$\mathrm{Na}$ reprodução simples o pressuposto é de que os capitalistas utilizam toda o seu mais-valor para consumo pessoal, não há, portanto, acumulação de capital. Assim, a construção teórica feita por Marx assume cinco hipóteses: (i) todo mais-valor é consumido na forma de meios de consumo pelos capitalistas; (ii) a composição orgânica do capital, nos dois departamentos, é constante, logo, não há aumento de produtividade; (iii) a taxa de mais-valor, nos dois departamentos é a mesma e constante; (iv) as mercadorias são trocadas pelos seus valores, portanto, não temos aqui interferências produzidas por modificações de preços; (v) os capitalistas dispõem de reservas ilimitadas de força de trabalho. (GIUSSANI, 1988). 
Em termos genéricos os esquemas da reprodução simples podem ser representados conforme a Figura 2.

\title{
FIGURA 2 - BALANÇO NA REPRODUÇÃO SIMPLES
}

\author{
Departamento I : $c_{I}+v_{I}+m_{I}=p_{I}$ \\ Departamento II : $\vec{c}_{I I}+v_{I I}+m_{I I}=p_{I I}$
}

FONTE: Elaboração própria.

Na Figura 2, $c$ representa o capital constante, $v$ o capital variável, $m$ o mais-valor, $p$ a produção total de cada departamento e os subíndices I e II representam os departamentos de produção de meios de produção e de meios de consumo, respectivamente. Os elementos delimitados pelos quadrados representam a condição de proporcionalidade, ou balanço, exigida para que a reprodução simples ocorra sem interrupções, isto é, que a reprodução social encontre todos os elementos necessários de reposição do capital adiantado e de consumo pessoal das classes. Em termos algébricos o balanço da reprodução simples é:

$$
c_{I I}=v_{I}+m_{I} \quad \text { Equação de balanço } 1
$$

Ou seja, para que essa economia hipotética possa continuamente produzir e distribuir os produtos entre as duas classes envolvidas, capitalistas e trabalhadores, é preciso que o capital constante do departamento II ( $\left.c_{I I}\right)$ seja igual à soma do capital variável e do mais-valor do departamento I $\left(v_{I}+m_{I}\right)$, tanto do ponto de vista do valor como do ponto de vista do valor de uso. A produção representada por $c_{I}$ deve ser consumida dentro do departamento I, a fim de repor o capital constante do departamento I.

A produção representada por $v_{I I}+m_{I I}$ deve ser consumida dentro do departamento II, a fim de satisfazer as necessidades de consumo de capitalistas e trabalhadores deste departamento, portanto, $c_{I}$ e $v_{I I}+m_{I I}$ não participam do intercâmbio entre departamentos e, por isso, rupturas entre compras e vendas intrasetoriais contém possibilidades de crise que se manifestam dentro de cada departamento. Veremos no item 3.1.1 que o intercâmbio dentro do departamento II também impõe possibilidades de crise da reprodução social, pois requer condições de balanço que envolvem os dois departamentos.

A contradição principal que guia o movimento da reprodução social é a unidade entre compra e venda entre os departamentos. A condição de balanço da reprodução simples requer que o departamento I venda ao departamento II uma quantidade de meios de produção igual a $C_{I I}$. Do ponto de vista do departamento II esta operação representa 
uma compra. Mas não é esta oposição venda/compra que constitui a contradição da reprodução social, já que esta oposição é apenas uma identidade contábil, se a venda ocorre, necessariamente, a compra ocorre. A contradição reside no fato de que o departamento I depois de vender a quantidade $C_{I I}$ ao departamento II deve comprar do departamento II a quantidade $v_{I}+m_{I}$ na forma de meios de consumo para satisfazer as necessidades pessoais dos capitalistas e trabalhadores deste departamento. Então, a venda seguida da compra realizadas pelo departamento I constitui uma contradição, pois, são elementos opostos (venda x compra) que mantém uma unidade interna (necessária), mas cuja unidade pode se dissociar, a qualquer momento e por diversas razões, de modo que a compra não se suceda à venda inicial. Se isso ocorrer haverá uma desproporção entre os dois departamentos e isso coloca a possibilidade de crise, ou seja, essa contradição contém a forma abstrata da crise.

Do mesmo modo, do ponto de vista do departamento II existe uma contradição semelhante. O departamento II deve comprar do departamento I uma quantidade de meios de produção igual a $c_{I I}$, pois é necessário repor o capital constante dispendido no início do processo. E o departamento II precisa vender ao departamento I uma quantidade de meios de consumo para satisfazer as necessidades pessoais dos capitalistas e trabalhadores do departamento I, igual a $v_{I}+m_{I}$. Portanto, a unidade entre compra e a venda por parte dos capitalistas do departamento II consiste em uma contradição, a possibilidade da venda não suceder a compra consiste na possibilidade de crise ou a forma abstrata da crise.

Mas, se tanto o departamento I como o II precisam repor suas condições de produção e precisam satisfazer as necessidades de consumo pessoal de trabalhadores e capitalistas, haveria alguma razão (ou razões) imposta pela própria natureza da reprodução, para que as compras não se sucedam às vendas e vice-versa? Na análise da reprodução simples Marx identifica pelo menos duas dificuldades impostas pela própria natureza da reprodução social no capitalismo que fazem com que o balanço entre os departamentos possa se converter em condição de não-balanço. A primeira está no intercâmbio dentro do departamento II, que envolve a proporção entre meios de consumo necessários e de luxo; e a segunda é o processo de formação do fundo de depreciação e seu oposto, isto é, a renovação do capital fixo in natura.

\subsubsection{O Intercâmbio dentro do Departamento II}

À primeira vista pode-se pensar que o intercâmbio dentro do departamento II não pode oferecer risco para a reprodução do capital social. Entretanto, a análise de Marx nos leva a um desdobramento da equação de balanço 1 em duas outras equações de balanço e, portanto, em duas outras possibilidades de não balanço, ou seja, possibilidades de crise.

O intercâmbio dentro do departamento II mostra a circulação das partes de valor $v_{I I}$ e $m_{I I}$. Marx divide o departamento II em subdepartamentos: o subdepartamento IIa, que 
produz meios de consumo necessários ${ }^{3}\left(\mathrm{M}_{\mathrm{n}}\right)$; e o subdepartamento IIb, que produz meios de consumo excedentes ou de luxo $\left(\mathrm{M}_{\mathrm{x}}\right)$. A Figura 3 traz o exemplo numérico de Marx:

\section{FIGURA 3 - ESQUEMA DA REPRODUÇÃO SIMPLES COM SUBDEPARTAMENTOS IIa E IIb}

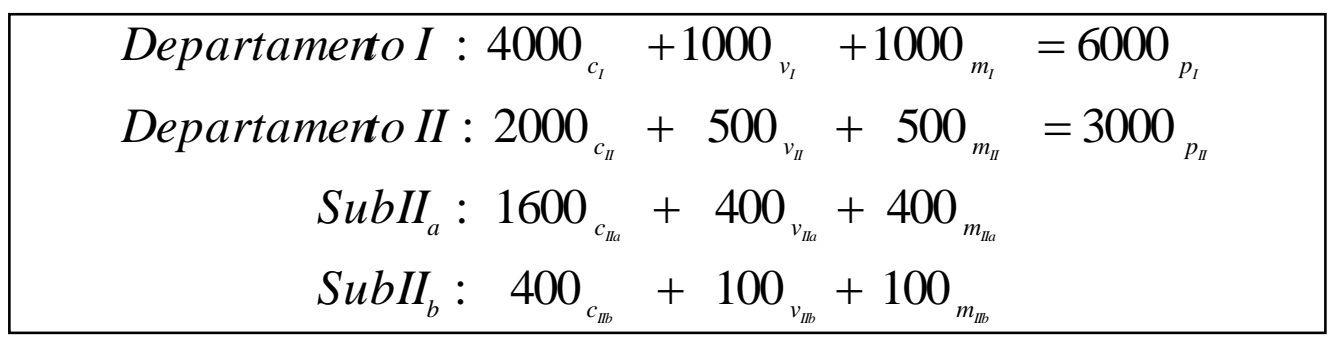

FONTE: Elaboração própria.

Para analisar como se dá o intercâmbio entre os subdepartamentos Marx supõe que os capitalistas dividem seus gastos de consumo em 3/5 da mais valia em meios de consumo necessários $\left(M_{n}\right)$ e 2/5 da mais valia em meios de consumo de luxo $\left(M_{x}\right)$, conforme mostra a Figura 4:

\section{FIGURA 4 - DIVISÃO DA MAIS VALIA EM MEIOS DE CONSUMO NECESSÁRIOS E DE LUXO}

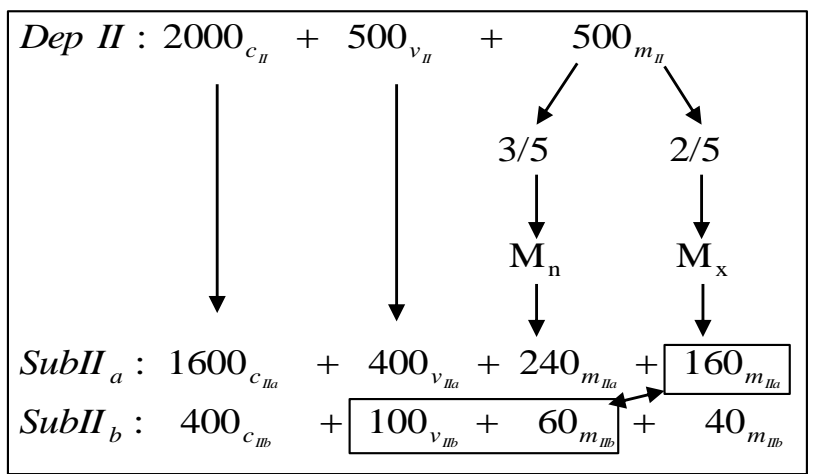

FONTE: Adaptado de Cipolla (2020)

\footnotetext{
${ }^{3}$ Os meios de consumo necessários são aqueles que entram no consumo da classe trabalhadora e em parte no consumo da classe capitalista. Os meios de consumo excedentes ou de luxo são aqueles que entram exclusivamente no consumo da classe capitalista (Marx, 1985, II, p. 298)
} 
O consumo de meios necessários dos trabalhadores e dos capitalistas do departamento IIa é realizado dentro do próprio subdepartamento. O consumo de meios de luxo dos capitalistas IIb é realizado dentro do próprio subdepartamento IIb. Então, seguindo a formalização feita por Cipolla (2020), se definirmos como $\lambda$ a proporção da mais valia gasta em meios de consumo necessários $\left(\mathrm{M}_{\mathrm{n}}\right)$ e como $(1-\lambda)$ a proporção da mais valia gasta em meios de consumo de luxo $\left(\mathrm{M}_{\mathrm{x}}\right)$ a condição de balanço dentro do Departamento II será:

$$
v_{\mathrm{IIb}}+\lambda m_{\mathrm{IIb}}=(1-\lambda) m_{\mathrm{IIa}} \quad \text { Equação de balanço } 2
$$

Se aplicarmos esta formalização para o departamento I podemos visualizar como a divisão da mais valia em consumo necessário e de luxo afeta a condição de balanço entre os departamentos I e II. A Figura 4 representa estas condições:

\section{FIGURA 5 - CONDIÇÕES DE BALANÇO DA REPRODUÇÃO SIMPLES}

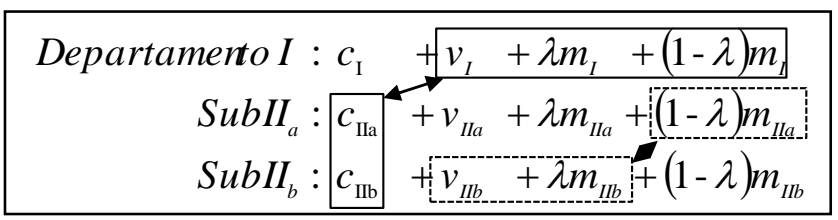

FONTE: Adaptado de Cipolla (2020)

A equação de balanço da reprodução simples entre os departamento I e II pode ser reescrita como:

$$
c_{\text {IIa }}+c_{\text {IIb }}=v_{\mathrm{I}}+\lambda m_{\mathrm{I}}+(1-\lambda) m_{\mathrm{I}} \quad \text { Equação de balanço } 3
$$

Cipolla (2020) observa que a equação 3 contém duas condições de balanço diferentes, mas que devem operar simultaneamente para que o balanço entre os departamentos ocorra. A parcela da mais valia dos capitalistas do departamento I a ser gasta com meios de consumo de luxo $\left[(1-\lambda) m_{\mathrm{I}}\right]$ só pode ser intercambiada com a parcela referente aos meios de produção desejados pelos capitalistas do departamento IIb, pois é neste subdepartamento que são produzidos os meios de consumo de luxo $\left(c_{\mathrm{IIb}}\right)$. Do mesmo modo, a parcela de salários dos trabalhadores e de mais valia dos capitalistas a serem gastas com meios de consumo necessários $\left(v_{\mathrm{I}}+\lambda m_{\mathrm{I}}\right)$ que representam meios de produção do departamento I só podem ser intercambiados com o departamento IIa $\left(c_{\text {III }}\right)$, pois é neste subdepartamento que se produzem meios de consumo necessários, portanto, dentro da equação de balanço 3 temos duas subcondições da condição geral de balanço entre I e II:

$$
\begin{array}{ll}
c_{\mathrm{IIb}}=(1-\lambda) m_{\mathrm{I}} & \text { Equação de balanço } 4 \\
c_{\text {III }}=\lambda m_{\mathrm{I}}+v_{\mathrm{I}} & \text { Equação de balanço } 5
\end{array}
$$


Das equações 4 e 5 , podemos tirar uma conclusão parcial de que a possibilidade de ruptura está posta apenas se a decisão em relação à proporção do consumo dos capitalistas entre meios necessários e de luxo mudar, já que o consumo de meios necessários por parte dos trabalhadores só pode mudar se o próprio valor da força de trabalho mudar, mas é um pressuposto da reprodução simples que os valores permanecem constantes, e do mesmo modo, a suposição de que a escala de produção não muda garante que as demandas por capital constante também não mudam, portanto, a única possibilidade de que o balanço não ocorra é dada por mudanças no consumo capitalista. Por exemplo, na equação 4 se os capitalistas do departamento I decidirem consumir meios de luxo numa proporção menor ou maior que $(1-\lambda)$ ocorre uma dissociação entre compra e venda entre I e IIb. O mesmo ocorre na equação 5, se os capitalistas de I decidirem consumir uma proporção maior ou menor de meios necessários que $\lambda$, então ocorre uma dissociação entre as compras e vendas entre I e IIa.

Portanto, toda a exposição de Marx sobre o intercâmbio envolvendo meios de consumo necessários e de luxo, cujo intuito é mostrar as condições de balanço entre os departamentos nos demonstram, ao mesmo tempo, as condições de não balanço, logo, concluímos que a unidade entre as compras e vendas contém, na sua própria origem, a possibilidade de ruptura, portanto, contém em germe a forma abstrata da crise.

\subsubsection{A Formação do Fundo de Depreciação e a Reposição do Capital Fixo in natura}

Para compreender melhor a dificuldade imposta à reprodução pela necessidade de formação do fundo de depreciação, por um lado, e da substituição do capital fixo in natura, por outro, vamos partir do exemplo numérico da equação de balanço entre os departamentos, apresentado por Marx:

FIGURA 6 - EXEMPLO NUMÉRICO DA REPRODUÇÃO SIMPLES

\begin{tabular}{|c|c|}
\hline $\begin{array}{l}\text { Departamento I : } 4000_{c_{I}}+1000_{v_{I}}+1000_{m_{I}} \\
\text { Departamento II : } 2000_{c_{I}}+500_{v_{I}}+500_{m_{I I}}\end{array}$ & $\begin{array}{l}=6000_{p_{I}} \\
=3000_{p_{I I}}\end{array}$ \\
\hline
\end{tabular}

FONTE: Elaboração própria.

Marx percebe que na troca entre o departamento I $\left(1000 v_{I}+1000 m_{I}\right)$ e o departamento II $\left(2000 c_{I I}\right)$ haveria necessariamente uma sobra no departamento I, uma vez que os capitalistas do departamento II não poderiam comprar toda a produção $\left(1000 v_{I}+\right.$ $1000 m_{I}$ ) do departamento I, pois se assim procedessem não seria possível reservar certa quantia de dinheiro para formar o fundo de depreciação: 
[...] a troca das mercadorias 2000IIc por mercadorias do mesmo valor I $(1000 \mathrm{v}+1000 \mathrm{~m})$ pressuporia que 2000IIc foram integralmente reconvertidos in natura nos elementos naturais do capital constante II, produzidos por I, mas o valor mercadoria de 2000 , em que existe este último, contém um elemento correspondente à perda de valor do capital fixo e que não é para ser reposto imediatamente in natura, mas para ser transformado em dinheiro que progressivamente se acumula como soma total, até que vença o prazo de renovação do capital fixo em sua forma natural. (...) Por isso, impõe-se imediatamente, na troca de I $(1000 \mathrm{v}+$ $1000 \mathrm{~m}$ ) por $2000 \mathrm{IIc}$, a dificuldade de que os meios de produção de I, em cuja forma natural os 2000(v + m) existem, têm de ser trocados por seu montante integral de valor de 2000 por equivalente em meios de consumo II, enquanto, por outro lado, os meios de consumo 2000IIc não podem ser convertidos por seu valor total nos meios de produção I $(1000 \mathrm{v}+1000 \mathrm{~m})$, por que uma parte alíquota de seu valor - igual à depreciação ou à perda de valor do capital fixo a ser reposto - tem de se depositar primeiramente em forma-dinheiro [...] (MARX, 1985, v. III, p. 331-332, destaque próprio).

Como o fundo de depreciação é parte orgânica do próprio processo de reprodução do capital, se ele não for formado paralelamente ao desgaste do capital fixo, a substituição deste no momento necessário ficaria comprometida e, portanto, comprometeria também o processo de reprodução do capital. Marx observa que este problema nunca havia sido tratado pela Economia Política, por isso, ele realiza um exaustivo exercício de análise de "todas as soluções possíveis (pelo menos aparentemente possíveis), ou melhor, os diferentes modos em que se coloca o problema." (MARX, 1985, v.III, p. 333). O objetivo de Marx é analisar as diversas possibilidades de intercâmbio que ao mesmo tempo pudessem garantir a formação do fundo de depreciação, a reposição do capital fixo in natura e, ainda, a preservação da lei do refluxo ${ }^{4}$. Marx analisa minuciosamente duas hipóteses principais. A primeira está representada na FIGURA 7 e supõe que o departamento I adiantaria dinheiro para realizar mercadorias do departamento II, mas que esse dinheiro não refluiria para I restando invendáveis mercadorias no valor de $200 m_{I}$, pois o departamento II retiraria da circulação $200 c_{d}$ :

\section{FIGURA 7 - INTERCÂMBIO ENTRE OS DEPARTAMENTOS CONSIDERANDO A NECESSIDADE DE FORMAÇÃO DO FUNDO DE DEPRECIAÇÃO}

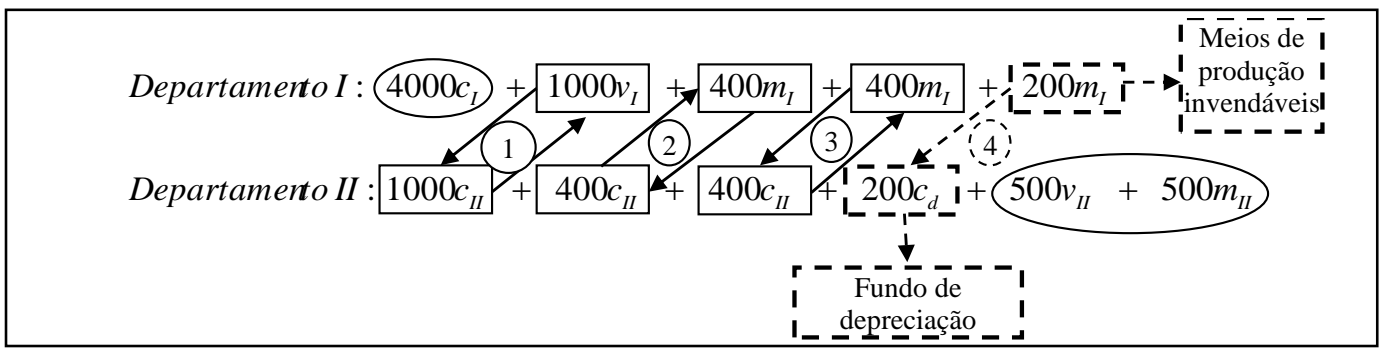

FONTE: Elaboração própria.

\footnotetext{
${ }^{4}$ A lei do refluxo mencionada por Marx significa que "o dinheiro que os produtores de mercadorias adiantam à circulação retorna a eles no decurso normal da circulação de mercadorias” (MARX, 1985, v. III, p. 305)
} 
A Figura 7 mostra quatro operações de adiantamento de dinheiro e aquisição de mercadorias, cujo objetivo é simular como o dinheiro poderia circular as mercadorias entre os dois departamentos e se esta circulação realizaria todo produto produzido, sem sobras em nenhum dos departamentos. Como já explicado as quantidades $4000 c_{I}$ e $500 v_{I I}+500 m_{I I}$ não participam do intercâmbio entre os departamentos, por isso estão representadas dentro de elipses e se resolvem dentro de cada departamento. Os valores que participam do intercâmbio estão representados dentro de quadrados e se realizam nas quatro operações indicadas pelos números que estão dentro dos círculos.

$\mathrm{Na}$ operação 1 Marx supõe que os capitalistas do departamento I adiantam dinheiro $^{5}$ no valor de $\$ 1.000$ pagando os salários dos trabalhadores ${ }^{6}$. Com esse salário os trabalhadores compram do departamento II meios de consumo, portanto, o dinheiro flui do departamento I para o departamento II. Os capitalistas do departamento II usam este mesmo dinheiro para comprar meios de produção no valor de $\$ 1.000$, de modo que o dinheiro adiantado pelos capitalistas do departamento I reflui para eles e um montante de mercadorias no valor de $\$ 2.000$ foi circulada $\left(1000 v_{I}\right.$ e $\left.1000 c_{I I}\right)$. Vale notar que aqui a lei do refluxo se verificou, isto é, o dinheiro adiantado pelos capitalistas do departamento I refluiu para eles.

Na operação 2 é a vez dos capitalistas do departamento II adiantarem dinheiro no valor de \$400 para adquirirem mais uma parte do capital constante necessário para repor suas condições de reprodução. O dinheiro flui de II para I. Com este dinheiro os capitalistas do departamento I realizam uma parte de sua mais valia adquirindo meios de consumo no valor de $\$ 400$, de modo que o dinheiro reflui ao departamento II que o havia adiantado e mercadorias no valor de $\$ 800$ são circuladas $\left(400 c_{I I}\right.$ e $\left.400 m_{I}\right)$. Aqui também a lei do refluxo se verifica.

Na operação 3 os capitalistas do departamento I adiantam $\$ 400$ em dinheiro para adquirir mais uma parte dos seus meios de consumo. Com este dinheiro os capitalistas de II adquirem mais uma parte dos meios de produção necessários de modo que o dinheiro adiantado reflui para I e mais $\$ 800$ em mercadorias são circuladas $\left(400 c_{I I}\right.$ e $\left.400 m_{I}\right)$. Aqui também a lei do refluxo se verifica.

Na operação 4 um problema se coloca. O departamento II precisa vender $200 c_{d}$ (que são meios de consumo), mas não pode comprar 200m (que são meios de produção), já que não tem necessidade destes meios de produção, porque precisa formar o fundo de depreciação e não substituir seu capital fixo in natura. Então, Marx supõe que os capitalistas do departamento I adiantam dinheiro para comprar $200 c_{d}$, mas esse dinheiro não reflui a I, pois os capitalistas do departamento II o entesouram para formar o fundo de

\footnotetext{
${ }^{5}$ Supõe-se que este dinheiro existe paralelamente ao capital produtivo adiantado no início do período.

${ }^{6}$ Não importa, para a análise, a ordem de quem inicia o adiantamento, o que importa é supor que ambos os departamentos realizem adiantamentos, pois do contrário seria arbitrária "a hipótese de que a classe capitalista I ou a classe capitalista II adianta unilateralmente à circulação o dinheiro necessário para conversão das mercadorias." (MARX, 1985, v. III, p. 335).
} 
depreciação, de modo que $200 m_{I}$ ficam invendáveis. Marx, depois de analisar detalhadamente as quatro operações, rejeita esta solução como sendo absurda ${ }^{7}$ e passa à análise de uma segunda hipótese "aparentemente mais absurda" que seria supor que o próprio departamento II "lança na circulação o dinheiro com que é convertida em prata a parte do valor das mercadorias a qual serve para repor a depreciação do capital fixo." (MARX, 1985, v. III, p. 335)

Marx considera essa hipótese apenas "aparentemente absurda", pois a "classe II consiste em capitalistas cujo capital fixo se encontra nos mais diversos estágios de sua reprodução.” (MARX, 1985, II, p. 335). Isto significa que os capitalistas do departamento II podem ser divididos em dois grupos: setor 1, que são capitalistas que se encontram no estágio de repor in natura seu capital fixo, portanto, possuem dinheiro disponível em seu fundo de depreciação já formado; setor 2 , que são capitalistas que se encontram no estágio de formar seu fundo de depreciação e seu capital fixo ainda está em funcionamento.

Partindo do exemplo da Figura 7, modificamos na Figura 8 as operações 3 e 4 da seguinte forma. Os capitalistas de tipo 1, do departamento II, já formaram seu fundo de depreciação no valor de $\$ 200$. Esses capitalistas de tipo 1 tem necessidade de repor seu capital constante circulante $(c c)$ e ainda adquirir novo capital fixo in natura (cf) e, em contrapartida, precisam vender $\$ 400$ em meios de consumo $\left(400 c_{I I}\right)$. Já os capitalistas de tipo 2 precisam somente vender $\$ 200$ em meios de produção $\left(200 c_{d}\right)$ e com o dinheiro formar seu fundo de depreciação. Então, a operação 3 indica o adiantamento por parte do departamento II, capitalistas de tipo 1, no valor de $\$ 600$ para adquirir meios de produção de mesmo valor, dos quais $\$ 400$ repõe capital constante circulante e \$ 200 repõe capital fixo in natura.

A operação 4 indica que o valor de $\$ 600$ flui para o departamento I que, com este dinheiro, adquire meios de consumo no valor de $\$ 600$, dos quais $\$ 400$ são adquiridos dos capitalistas do tipo 1 e $\$ 200$ são adquiridos dos capitalistas de tipo 2. Isto implica que os $\$ 600$ adiantados pelos capitalistas de tipo 1 do departamento II refluem para este departamento, mas não totalmente para os capitalistas de tipo 1 . Somente $\$ 400$ refluem para $\mathrm{II}_{1}$ e $\$ 200$ refluem para $\mathrm{II}_{2}$, de modo que os capitalistas $\mathrm{II}_{2}$ não compram meios de produção (pois não necessitam deles), mas vendem suas mercadorias e adquirem dinheiro para depositar no fundo de depreciação. Com estas suposições de balanço entre capitalistas de tipo $\mathrm{II}_{1}$ e $\mathrm{II}_{2}$ o intercâmbio entre os departamentos ocorre sem distúrbios.

\footnotetext{
7 “Isso contradiz não apenas o pressuposto da reprodução em escala simples; não é, em si e para si, uma hipótese para explicar a conversão em prata de $200 c_{d}$;mas antes pelo contrário, significa que ela não é explicável." (MARX, 1985, v. III, p. 334).
} 


\section{FIGURA 8 - INTERCÂMBIO ENTRE OS DEPARTAMENTOS CONSIDERANDO A EXISTÊNCIA DE CAPITALISTAS DO DEPARTAMENTO II DO TIPO 1 E 2}

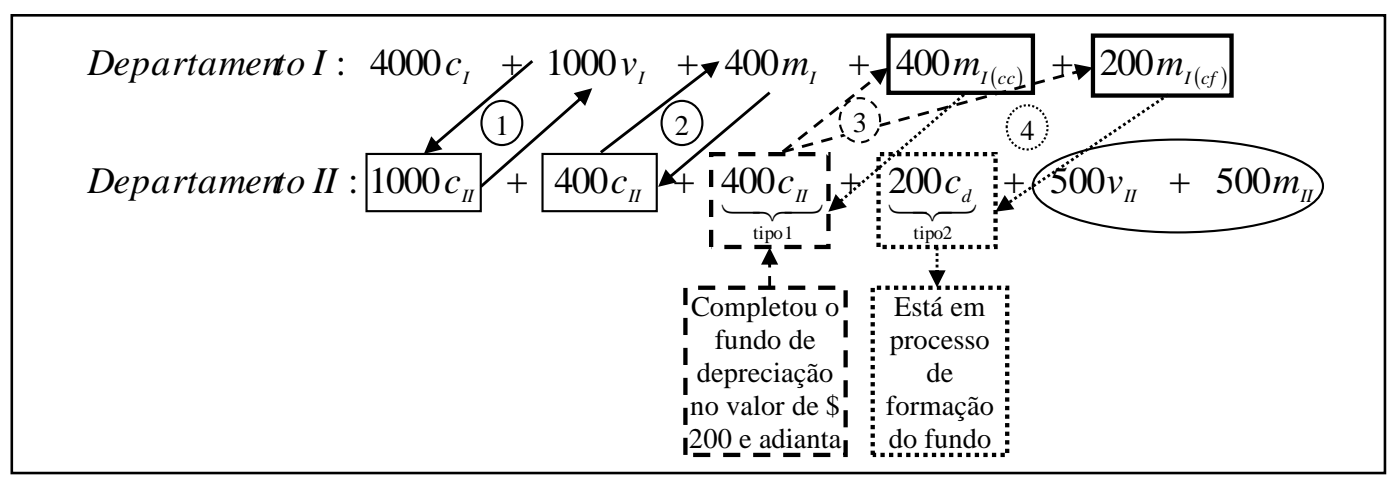

FONTE: Elaboração própria.

Assim, Marx considera o problema inicial de formação do fundo de depreciação e substituição do capital fixo in natura, resolvido. Contudo, vale notar que a condição de balanço entre capitalistas $\mathrm{II}_{1}$ e $\mathrm{II}_{2}$ traz consigo, ao mesmo tempo, condição de não balanço, já que não há nada que garanta esta coincidência.

Embora o problema da formação do fundo de depreciação possa ser resolvido supondo-se a existência de balanço entre capitalistas do tipo $\mathrm{II}_{1}$ e $\mathrm{II}_{2}$, Marx identifica mais um problema. A solução dada pelo uso da segunda hipótese resulta na necessidade de um equilíbrio

como lei da reprodução em escala constante; o que significa, em outras palavras, que na classe I, que produz meios de produção, a divisão proporcional de trabalho tem de permanecer inalterada, na medida em que fornece, por um lado, componentes circulantes, e, por outro, componentes fixos do capital constante do Departamento II. (MARX, 1985, v. III, p. 339).

Se o capital fixo que morre anualmente e que precisa ser renovado aumentar de um ano para o outro (por razões não previstas) a consequência é que, com a suposição de que a produção do departamento I é constante, para que este departamento atenda uma demanda crescente de capital fixo será necessário reduzir a produção de capital circulante. Mas se a produção de capital circulante for reduzida e, supondo que a produção no departamento II também deva ser constante, então com capital circulante menor o departamento II não pode manter o mesmo nível de produção dos meios de consumo, eis aí, uma dificuldade que, segundo Marx, só se resolve assim: 
Só se pode remediar isso mediante contínua superprodução relativa; por um lado, certo quantum de capital fixo que é produzido além do diretamente necessário; por outro lado, a saber, reserva de matéria prima etc., que supera as necessidades anuais imediatas (isso vale especialmente para meios de subsistência). Essa espécie de superprodução equivale ao controle da sociedade sobre os meios objetivos de sua própria produção. Dentro da sociedade capitalista, porém, ela constitui um elemento de anarquia. (MARX, 1985, I, p. 342).

Marx sugere, portanto, que o problema se resolve somente com a superação do próprio capitalismo, pois a desproporção entre capital fixo e circulante representa um problema apenas no contexto da propriedade privada dos meios de produção e não consiste em um problema para uma sociedade que tem o controle "sobre os meios objetivos de sua própria produção".

Contudo, dentro da lógica aqui desenvolvida de análise da possibilidade de crise, a solução encontrada por Marx indica a necessidade de mais um balanço - a quantidade de capital fixo que precisa ser continuamente renovado deve ser constante e igual a quantidade de dinheiro que continuamente entra no fundo de depreciação de modo que haja balanço entre a produção de capital fixo e circulante. Isso impõe, portanto, mais uma possibilidade de não balanço na reprodução do capital social. Temos, portanto, que o problema da formação do fundo de depreciação e, seu oposto, a substituição do capital fixo in natura, impõe à necessária unidade da compra e venda entre os departamentos duas possibilidades de não balanço: a possibilidade de que não haja balanço entre capitalistas do tipo $\mathrm{II}_{1} \mathrm{e} \mathrm{II}_{2} \mathrm{e}$ a possibilidade de que não haja balanço na produção do capital fixo e circulante.

\subsection{Reprodução Ampliada do Capital Social}

Todas as dificuldades analisadas sob a hipótese da reprodução simples se mantém quando passamos a analisar a reprodução ampliada e, além delas, acrescenta-se uma nova: a formação do fundo de acumulação. A transição da reprodução simples para a ampliada, isto é, para uma situação na qual parte do mais-valor é reinvestida no processo produtivo do ano seguinte, muda a condição de balanço para:

FIGURA 9 - BALANÇO NA REPRODUÇÃO AMPLIADA GERAL

$$
\begin{array}{|lcl|}
\hline \text { Departamento I : } & c_{I}+k_{c} m_{I}+v_{I}+k_{v} m_{I}+\left(1-k_{c}-k_{v}\right) m_{I} \\
\text { Departamento II : } & c_{I I}+k_{c} m_{I I}+v_{I I}+k_{v} m_{I I}+1-\left(k_{c}+k_{v}\right) m_{I I} \\
\hline
\end{array}
$$

FONTE: Adaptado de Giussani (1988). 
A Figura 9 indica que o mais-valor não é totalmente consumida, mas é dividida entre o consumo pessoal do capitalista e a acumulação de capital. O consumo capitalista é representado por $\left(1-\mathrm{k}_{\mathrm{c}}-\mathrm{k}_{\mathrm{v}}\right) \mathrm{m}$, onde $\mathrm{k}_{\mathrm{c}}$ representa a proporção do mais-valor a ser reinvestida como capital constante e $\mathrm{k} v$ a proporção da mais valia a ser reinvestida em capital variável. Assim, as condições de balanço algébrico na reprodução ampliada geral mudam para:

$$
c_{\mathrm{II}}+\mathrm{k}_{c} m_{\mathrm{II}}=v_{\mathrm{I}}+\left(1-\mathrm{k}_{c}\right) m_{\mathrm{I}} \quad \text { Equação de balanço } 6
$$

A necessidade de formação de um fundo de acumulação coloca uma dificuldade semelhante àquela imposta pela formação do fundo de depreciação, já analisada no item 3.1.2:

\begin{abstract}
Dinheiro é retirado da circulação e acumulado como tesouro mediante a venda da mercadoria sem compra subsequente. Se concebemos essa operação como sendo praticada em geral, parece impossível verificar de onde devem vir os compradores, uma vez que nesse processo - e ele deve ser concebido como geral, em que cada capital individual pode encontrar-se em processo de acumulação - cada um quer vender a fim de entesourar, e ninguém quer comprar. (MARX, 1985, v. III, p. 358).
\end{abstract}

Contudo, Marx oferece para este problema uma solução semelhante àquela proposta para a formação do fundo de depreciação. É preciso supor que enquanto uma parte dos capitalistas está retendo dinheiro para formar o fundo de acumulação a outra parte está liberando dinheiro anteriormente retido e adquirindo capital constante e variável novos para ampliar o processo produtivo. Ou seja, é necessário pressupor que haja um balanço entre os fluxos de entrada e saída de dinheiro destinados à formação do fundo de acumulação. Portanto, aqui como nas dificuldades já analisadas, a possibilidade de crise está inscrita na dissociação entre compra e venda que decorrem da aleatoriedade dos diversos balanços necessários para que a reprodução do capital social decorra sem interrupções.

Assim, com o estudo dos esquemas da reprodução torna-se evidente que a necessidade de formação do fundo de depreciação e de acumulação contém as formas abstratas das crises, pois as diversas condições de balanço exigidas demostram a possibilidade de que compras se sucedem às vendas, mas apontam, ao mesmo tempo, que dada a natureza atomizada, individualizada, portanto, não planejada, das decisões individuais no capitalismo o balanço só ocorre como resultado de diversos ajustes.

\title{
3.3. Planejamento da Produção e Possibilidade de Crise
}

No início da seção sobre a reprodução simples havíamos colocado cinco pressupostos: (i) toda mais valia é consumida na forma de meios de consumo pelos capitalistas; (ii) a composição orgânica do capital, nos dois departamentos, é constante; (iii) a taxa de mais-valor, nos dois departamentos é a mesma e constante; (iv) as mercadorias são trocadas pelos seus valores; (v) os capitalistas dispõem de reservas ilimitadas de força 
de trabalho. A análise da reprodução ampliada eliminou o primeiro pressuposto e já vimos seu resultado, agora vejamos as implicações, no que se refere às possibilidades de crise, da flexibilização dos demais pressupostos.

Se considerarmos que a composição do capital, ao invés de se manter constante, se modifica tal como estabelecido pela lei geral da acumulação capitalista, teremos que a condição geral de balanço entre os departamentos passa a ser determinada por uma condição secundária que é a modificação proporcional das composições nos dois departamentos. Isto significa que é preciso haver mais uma condição de balanço que garanta que aumentos da composição do capital no departamento I, que resultarão em maior produtividade em I, serão acompanhados por aumentos na composição do capital no departamento II fazendo com que este também demande mais meios de produção. Mas como não há este planejamento entre os setores as modificações aleatórias na composição do capital produzem um descompasso entre demanda e oferta, entre compra e venda e, portanto, colocam novas possibilidades de crise.

$\mathrm{O}$ mesmo efeito ocorre em relação à taxa de mais valia. Se os capitalistas do departamento I aumentarem a exploração do trabalho isso fará os trabalhadores produzirem mais valores de uso do que antes (mais meios de produção), entretanto o departamento II não terá, necessariamente, uma demanda maior por meios de produção, resultando em uma sobra destas mercadorias no departamento I e, portanto, uma dissociação entre compras e vendas, pois não há um planejamento do crescimento das taxas de mais valia entre os departamentos.

As modificações de preços, que não expressam modificações nos valores, também dissociam compras e vendas. Se a transformação de $\mathrm{D}$ em $\mathrm{M}$ (meios de produção e força de trabalho) ocorre a certos preços e a transformação de M' em D' ocorre a preços inferiores haverá uma dissociação entre compras e vendas entre os departamentos e, portanto, coloca possibilidades de crise.

Se houver, por alguma razão, escassez de força de trabalho os salários aumentarão e o balanço entre as compras e vendas será perturbado, pois com salários maiores os trabalhadores demandarão mais meios de consumo e o departamento II não estará preparado para ofertá-los, pois isso não foi planejado. O mesmo raciocínio vale para excesso de força de trabalho.

Concluímos, portanto, que para ocorrer o processo de reprodução do capital social sem interrupções é preciso que haja diversas condições de balanço ocorrendo simultaneamente, portanto, não nos deve surpreender que crises periódicas ocorram sistematicamente no capitalismo, já que estas condições de balanço simultâneas somente seriam possíveis a partir de um rigoroso planejamento da produção. Contudo, devemos estar atentos aos limites possíveis de aplicação de planejamento à economia capitalista. Tendo em vista a natureza do modo de produção capitalista pautada na garantia da propriedade privada dos meios de produção e na desejada liberdade dos capitalistas em buscar o lucro um planejamento que estabelece limites e proporções das taxas de mais valia, das composições do capital, das variações dos preços, da formação dos fundos de depreciação e acumulação etc. entre os departamentos parece totalmente incompatível com 
o movimento do próprio capital.

\section{Considerações Finais}

O objetivo deste artigo foi mapear as contradições do processo de reprodução do capital, no nível abstrato permitido pelo uso dos esquemas de reprodução de Marx, a fim de identificar as possibilidades de crise nele inscritas. Tomamos como definição da contradição a unidade e a dissociação das compras e vendas entre os departamentos e a possibilidade de crise como sendo a forma mais abstrata da crise contida na dissociação entre as compras e vendas, e contidas, também, nas formas mais concretas da crise.

A análise dos esquemas de reprodução de Marx nos permitiu mapear as seguintes condições de balanço das compras e vendas (a unidade entre compras e vendas) entre os departamentos: entre consumo de meios necessários e meios de luxo por parte dos capitalistas; entre os capitalistas de tipo 1 e 2 no departamento II na formação do fundo de depreciação e de reposição do capital fixo in natura; entre oferta e demanda de capital fixo e capital constante entre os departamentos; entre os capitalistas de tipo 1 e 2 na formação do fundo de acumulação; na modificação das composições do capital entre os departamentos; na modificação das taxas de mais valia entre os departamentos; na modificação dos preços relativos entre os departamentos; na oferta e demanda por força de trabalho entre os departamentos. Todas estas condições de balanço contém a forma abstrata da crise, pois contém unidades de compra e venda que se dissociam por motivações do próprio movimento da reprodução do capital, assim, as condições de balanço são ao mesmo tempo condições de não balanço.

As crises periódicas do capitalismo revelam que essas condições de balanço só ocorrem por mera coincidência, já que a natureza anárquica do modo de produção de mercadorias é incompatível com o planejamento da produção. As crises do capitalismo, e , portanto, todos os efeitos negativos que elas impõe sobre a classe trabalhadora, só podem ser superadas com a superação do próprio capitalismo.

\section{Referências}

ALTHUSSER, L. Contradição e Sobredeterminação. In: ALTHUSSER, L. Análise crítica da teoria marxista. Rio de Janeiro: Zahar Editores, 1967.

ARTHUR, C. J. Hegel's Logic and Marx Capital. In: MOSELEY, F. (Ed.) Marx's method in Capital: a reexamination. New Jersey: Humanities Press, 1993.

BARAN, P.; SWEEZY, P. Capitalismo monopolista. Tradução por: Waltensir Dutra. Rio de Janeiro: Zahar Editores, 1966. 
BHASKAR, R. (1988). Contradição. In: BOTTOMORE, T. (Ed.) Dicionário do pensamento marxista. Tradução por: Waltensir Dutra. Rio de Janeiro: Zahar Editores, 1988.

BLEANEY, M. F. Underconsumption Theories: A History and Critical Analysis. New York: International Publishers, 1976.

CARCHEDI, G. Marx's Logic of Inquiry and Price Formation. In: MOSELEY, F. (Ed.) Marx's method in Capital: a reexamination. New Jersey: Humanities Press, 1993.

CIPOLLA, F. Reprodução simples. Video aula 23 produzida para estudantes da graduação em Ciências Econômicas da Universidade Federal do Paraná, 2020. Disponível em: http://www.leiturasdocapital.ufpr.br/?page id=641

COLLETTI, L. Marxism and the Dialectic. New Left Review, I/93, September-October, 1975 .

GODELIER, M. Estrutura e contradição no Capital. In: BLACKBURN, R. (ed.)

Ideologia na Ciência Social: ensaios críticos sobre a teoria social. Tradução por: Aulyde Rodrigues. Rio de Janeiro: Paz e Terra, 1982.

GORENDER, J. Apresentação. In: MARX, K. O Capital: crítica da economia política. Livro I. 2. ed., São Paulo: Nova Cultural. (Coleção Os Economistas, livro primeiro, v. I), 1985 .

GRESPAN, J. O negativo do Capital: o conceito de crise na crítica de Marx à Economia Política. $2^{a}$ edição, São Paulo: Expressão Popular, 2012

GIUSSANI, P. Esquemas de Reprodução. In: BOTTOMORE, T. Dicionário do Pensamento Marxista. Rio de Janeiro: Jorge Zahar Editor, 1988.

HILFERDING, R. O capital financeiro. Tradução por: Reinaldo Mestrinel. São Paulo: Nova Cultural. (Coleção Os Economistas), 1985.

ITOH, M. Value and Crisis. New York: Monthly Review Press, 1980.

LÊNIN, V. I. On the Question of Dialectics. Collected Works, $4^{\text {th }}$ English Edition, Moscow: Progress Publishers, v. 38, pp.355-364, 1972. Disponível em: http://www.marx2mao.com/Lenin/QD15. html.

LUXEMBURGO, R. A acumulação de capital: contribuição ao estudo econômico do Imperialismo. Tradução por: Marijane Vieira Lisboa e Otto Erich Walter Maas. São Paulo: Nova Cultural. (Coleção Os Economistas), 1985. 
MAO TSÉ-TUNG. On Contradiction. Selected Works of Mao Tse-Tung, 1937.

Disponível em: http://www.marxists.org/reference/archive/mao/selected-works/volume$\underline{1 / \mathrm{mswv} 1} 17 . \mathrm{htm}$.

MARX, K. Teorias da mais-valia: história crítica do pensamento econômico. Livro 4 de O Capital. Tradução por: Reginaldo Sant’Anna. v. 2, São Paulo: DIFEL, 1980.

MARX, K. O Capital: crítica da economia política. Tradução de: Regis Barbosa e Flávio R. Kothe. Livro I e II. 2. ed., São Paulo: Nova Cultural. (Coleção Os Economistas, v. I, II e III), 1985

MARX, K. O Capital: crítica da economia política. Tradução de: Regis Barbosa e Flávio R. Kothe. Livro III. 2. ed., São Paulo: Nova Cultural. (Coleção Os Economistas, livro terceiro, v. IV e V), 1986.

MARX, K. Grundrisse: Foundations of the Critique of Political Economy. Tradução por: Martin Nicolaus. London: Penguin Books, 1993.

SMITH, T. Marx's Capital and Hegelian Dialectical Logic. In: MOSELEY, F. (Ed.). Marx's Method in Capital: a reexamination. New Jersey: Humanities Press, 1993.

SHAIKH, A. An Introduction to the History of Crisis Theories. U.S. capitalism in crisis, New York: URPE, 1979.

ZELENZÝ, J. La estrutura lógica de "El Capital” de Marx. Tradução por: Manuel Sacristán. Buenos Aires: Grijalbo, 1974.

ZONINSEIN, J. Capital Financeiro, demanda efetiva e causas da crise. Ensaios FEE, v. 6, n. 1, Porto Alegre, 1985. Disponível em: https://revistas.dee.spgg.rs.gov.br/index.php/ensaios/article/view/897 